\title{
Identifikasi Potensi Glaukoma Dan Diabetes Retinopati Melalui Citra Fundus Menggunakan Jaringan Syaraf Tiruan
}

\author{
Muhammad Ezar Al Rivan*1, Tegar Juangkara ${ }^{2}$ \\ ${ }^{1,2}$ STMIK Global Informatika MDP; Jalan Rajawali No. 14, (0711) 376400 \\ ${ }^{1,2}$ Program Studi Teknik Informatika, STMIK Global Informatika MDP, Palembang \\ e-mail: *11 meedzhar@mdp.ac.id, ${ }^{2}$ thecastaway09@gmail.com
}

\begin{abstract}
Abstrak
Identifikasi potensi glaukoma dan retinopati diabetes dapat dilakukan melalui citra fundus. Jaringan syaraf tiruan dapat digunakan untuk mengidentifikasi potensi glaukoma dan diabetes retinopati. Dataset yang digunakan berjumlah 60 citra fundus yang terdiri dari 20 citra fundus terjangkit glaukoma, 20 citra fundus terjangkit diabetes retinopati dan 20 citra fundus mata normal. Hasil penelitian menghasilkan rata-rata untuk recall sebesar 86,6\%, precission sebesar 86,6\%, dan untuk accuracy sebesar 91,06\%.
\end{abstract}

Kata kunci-Identifikasi, Glaukoma, Diabetes Retinopati, Fundus, Jaringan Saraf Tiruan

\begin{abstract}
Glaucoma and diabetic retinopathy identification conduct form fundus image. Artificial Neural Network can be used as algorithm to identify glaucoma and diabetic retinopathy. Dataset contains 60 fundus image consist of 20 glaucoma fundus image, 20 diabetic retinopathy fundus images and 2- normal fundus image. The result are 86,6\% for average recall, 86,6\% for average precision and 91,06\% for average accuracy.
\end{abstract}

Keywords-Identification, Glaucoma, Retinopathy diabetic, Fundus, Artificial Neural Network

\section{PENDAHULUAN}

laukoma merupakan suatu kondisi dari mata yang merusak pembuluh optik yang disebabkan

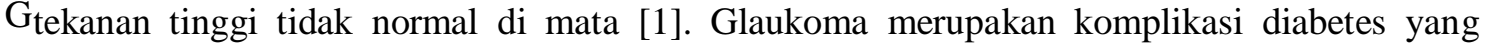
mempengaruhi mata yang menyebabkan kerusakan pembuluh darah pada jaringan mata [2]. Glaukoma dan diabetes retinopati dapat diketahui dari citra fundus.

Penelitian yang dilakukan yaitu mendeteksi glaukoma dan diabetes retinopati menggunakan citra fundus telah dilakukan oleh [3] menggunakan template matching. Selain itu penelitian lainnya dilakukan oleh [4] menggunakan metode K-NN. Penelitian lain dilakukan juga oleh [5] menggunakan K-NN. Penelitian yang dilakukan [6] menggunakan fitur color histogram dan transformasi wavelet namun menggunakan jaringan syaraf tiruan sebagai classifier. Penelitian yang dilakukan [7] menggunakan citra fundus dengan jaringan saraf tiruan sebagai classifier. Jaringan syaraf tiruan digunakan untuk melakukan klasifikasi penyakit mata 
[8]. Penelitian tersebut memberikan hasil yang baik. Pada penelitian lain yang dilakukan oleh [9] juga menggunakan jaringan syaraf tiruan untuk mengklasifikasikan katarak. Dari hasil penelitian tersebut diperoleh hasil yang baik. Citra fundus penderita glaukoma dan diabetes retinopati digunakan sebagai input dari sistem. Penelitian lain mengenai. Data diperoleh dari sumber internet High-Resolution Fundus (HRF) Image Database [10]. Data yang diperoleh sebanyak 60 citra fundus, dimana terdiri dari 20 citra terjangkit glaukoma, 20 citra terjangkit retinopati diabetes, dan 20 citra mata normal. Masing-masing data akan melewati proses pelatihan, dan pengujian pada dataset.

Dibandingkan dengan penelitian sebelumnya, pada penelitian ini data yang digunakan tidak melalui ekstraksi fitur. Proses ekstraksi fitur telah

dilakukan oleh [10] yang menghasilkan binary image. Terlihat perbedaan antara pembuluh darah dan bukan pembuluh darah. Ekstraksi fitur yang dilakukan oleh [10] telah diuji dengan metode-metode lain. Dari hasil pengujian tersebut metode yang diusulkan oleh [10] merupakan metode yang paling baik hasilnya. Dikarenakan bentuk fitur yang lebih sederhana dibandingkan fitur-fitur yang lain, binary fundus image dapat mengurangi komputasi. Dengan menggunakan input berupa fitur biner dapat mempermudah komputasi pada jaringan syaraf tiruan.

\section{METODE PENELITIAN}

Tahapan penelitian yang dilakukan untuk mengidentifikasi potensi glaukoma dan retinopati diabetes melalui citra fundus yakni identifikasi masalah, pengumpulan data, ekstraksi fitur, pelatihan, pengujian, dan analisis hasil.

\subsection{Identifikasi Masalah}

Masalah yang diidentifikasi adalah bagaimana menerapkan jaringan saraf tiruan untuk mengidentifikasi potensi glaukoma dan diabetes retinopati melalui citra fundus menggunakan jaringan syaraf tiruan.

\subsection{Pengumpulan Data dan Data Citra}

Pada tahap ini dilakukan pengumpulan data. Data citra fundus diperoleh dari sumber internet High-Resolution Fundus (HRF) image database dari universitas Friedrich Alexander Erlangen-Nuremberg di Jerman. Data yang diperoleh sebanyak 60 citra fundus, dimana terdiri dari 20 citra terjangkit glaukoma, 20 citra terjangkit diabetes retinopati dan 20 citra mata normal. Masing-masing data sudah melewati tahapan pre processing seperti peningkatan kualitas juga sudah dilakukan feature extraction. 


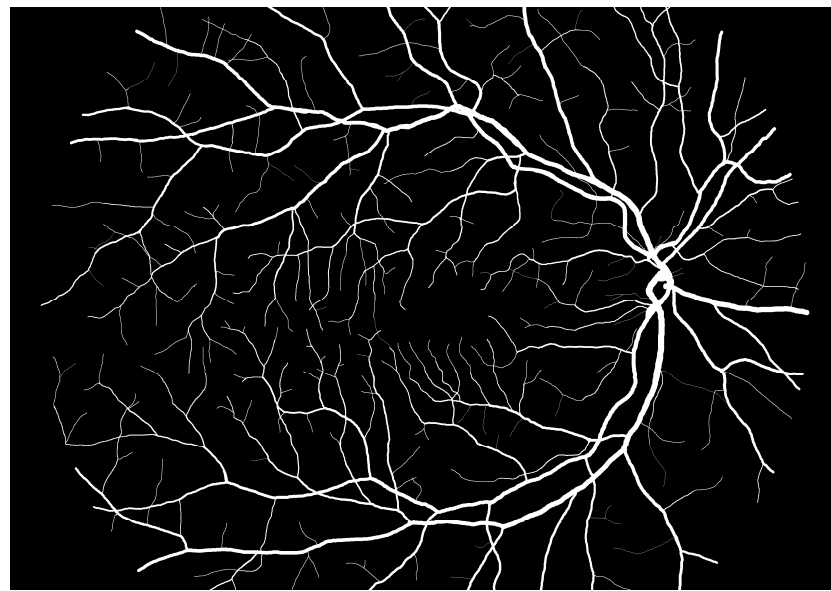

Gambar 1. Citra Fundus Mata Terjangkit Glaukoma

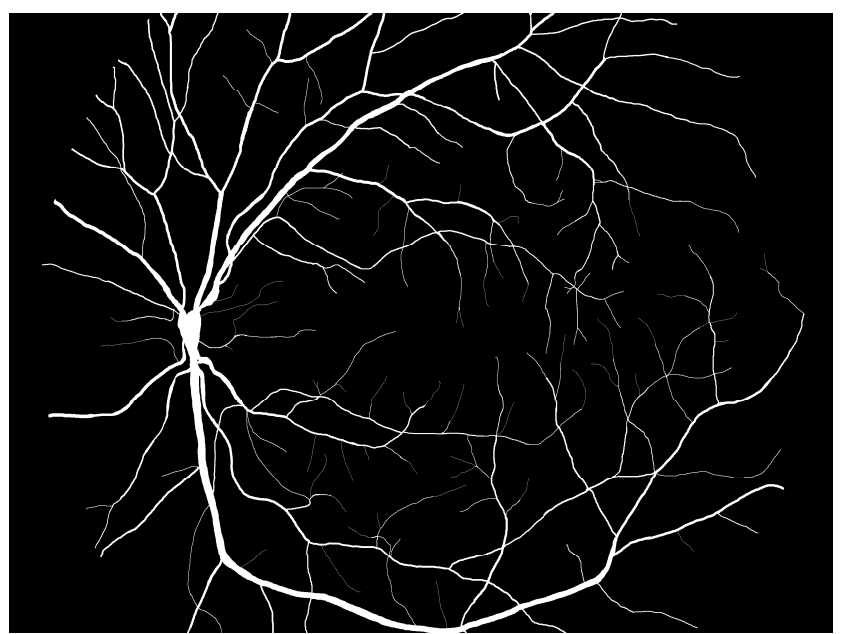

Gambar 2. Citra Fundus Mata Terjangkit Retinopati Diabetes

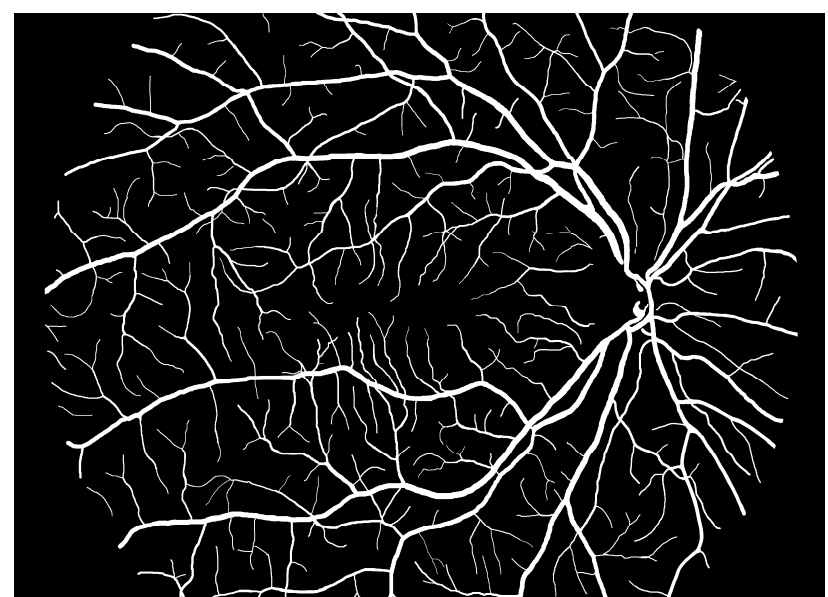

Gambar 3. Citra Fundus Mata Normal

Pada Gambar 1, 2 dan 3 adalah citra fundus mata terjangkit glaukoma, citra fundus mata terjangkit retinopati diabetes dan citra fundus mata normal. Perbedaan diantara citra tersebut terlihat dari citra fundus mata terjangkit glaukoma dan retinopati diabetes memiliki pembuluh darah yang lebih tipis dibandingkan dengan citra fundus mata normal. Hal ini dikarenakan

Al Rivan, et.al (Identifikasi Potensi Glaukoma dan Diabetes Retinopati Melalui Citra Fundus Menggunakan Jaringan Syaraf Tiruan) 
glaucoma dan retinopati diabetes disebabkan oleh tekanan besar pada bola mata yang menyebabkan tersumbatnya pembuluh darah yang menunjuk syaraf mata.

\subsection{Ekstraksi Fitur}

Ekstraksi fitur tidak dilakukan lagi dikarenakan citra yang diperoleh sudah dilakukan ekstraksi fitur.

\subsection{Pelatihan dan Pengujian}

Adapun pada tahapan proses pelatihan JST merupakan proses pembangunan sistem yang digunakan untuk melatih jaringan syaraf tiruan agar mampu mengidentifikasi potensi glaukoma dan retinopati diabetes. Data latih atau data yang digunakan untuk pelatihan berjumlah 15 citra untuk masing-masing penyakit. Jaringansaraftiruan yang telah dilatihakan diuji dengan menggunakan data uji. Data uji adalah data yang belum pernah dipakai untuk data pelatihan. Hasil dari pengujian adalah persentase peramalan, dan selanjutnya akan dilakukan analisis parameter jaringan terhadap akurasi hasil dari peramalan. Data uji atau data yang digunakan untuk pengujian berjumlah 5 citra.

\subsection{Evaluasi}

Setelah melakukan proses pelatihan dan pengujian dilanjutkan dengan evaluasi menggunakan metode precision, recall dan accuracy. Precision dan recall digunakan untuk mengukur kinerja sistem. Precision merupakan kecocokan antara bagian data yang diambil dengan informasi yang dibutuhkan. Recall merupakan tingkat keberhasilan sistem dalam menemukan kembali sebuah informasi. Accuracy merupakan tingkat kedekatan data antara nilai yang didapat terhadap nilai sebenarnya. Precision, recall dan accuracy dapat dihitung menggunakan confusion matrix.

Berdasarkan nilai True Negative (TN), False Positive (FP), False Negative (FN), dan True Positive (TP) dapat diperoleh nilai akurasi, presisi dan recall. Nilai akurasi menggambarkan seberapa akurat sistem dapat mengklasifikasikan data secara benar. Dengan kata lain, nilai akurasi merupakan perbandingan antara data yang terklasifikasi benar dengan keseluruhan data.

$$
\begin{gathered}
\text { Akurasi }=\frac{T P+T N}{T P+T N+F P+F N} * 100 \%(1) \\
\text { Presisi }=\frac{T P}{F P+T P} * 100 \%(2) \\
\text { Recall }=\frac{T P}{F N+T P} * 100 \%(3)
\end{gathered}
$$

TP adalah True Positive, yaitu jumlah data positif yang terklasifikasi dengan benar oleh sistem. TN adalah True Negative, yaitu jumlah data negatif yang terklasifikasi dengan benar oleh sistem. FN adalah False Negative, yaitu jumlah data negatif namun terklasifikasi salah oleh sistem. FP adalah False Positive, yaitu jumlah data positif namun terklasifikasi salah oleh sistem.

\section{HASIL DAN PEMBAHASAN}

Telah dilakukan pengujian menggunakan JST pada citra uji terdapat total 15 citra fundus yang digunakan untuk proses pengujian. Pada tahap penentuan hasil pengujian JST, dilakukan perhitungan secara confusion matrix untuk mendapatkan akurasi, precision dan 
recall. Berikut hasil dari pengujian JST yang ditampilkan dalam bentuk berupa tabel yang dapat dilihat pada Tabel 1. Beserta hasil perhitungan confusion matrix-nya, yang ditampilkan dalam bentuk berupa tabel yang dapat dilihat pada Tabel 2 .

Tabel 1 Hasil Pengujian JST denganTraingdx

\begin{tabular}{|c|l|c|c|c|}
\hline \multirow{2}{*}{\multicolumn{2}{|c|}{ Nama }} & \multicolumn{3}{c|}{ Target } \\
\cline { 3 - 5 } & $\begin{array}{c}1 \\
\text { Glaukoma }\end{array}$ & $\begin{array}{c}2 \\
\text { Normal }\end{array}$ & $\begin{array}{c}3 \\
\text { Retinopati Diabetes }\end{array}$ \\
\hline $\mathrm{O}$ & Glaukoma & 4 & 0 & 0 \\
$\mathrm{u}$ & & 1 & 5 & 1 \\
$\mathrm{n}$ & Normal & 0 & 0 & 4 \\
$\mathrm{nyyyy} \mathrm{u}$ & Retinopati & & & 0 \\
$\mathrm{t}$ & Diabetes & 0 & 0 & 5 \\
\hline \multicolumn{2}{|c|}{ Tidak Dikenali } & 5 & 5 & \\
\hline \multicolumn{2}{|c|}{ Jumlah } & & & \\
\hline
\end{tabular}

Tabel 1 merupakan hasil dari implementasi JST setelah dilakukan pengujian terhadap data latih. Setelah pengujian dilakukan maka selanjutnya dilakukan perhitungan untuk mengetahui tingkat akurasi pengenalan JST terhadap data uji menggunakan confusion matrix.

Tabel 2. Hasil Confusion Matrix denganTraingdx

\begin{tabular}{|c|c|c|c|c|c|c|c|}
\hline \multirow{2}{*}{ Nama } & \multirow{2}{*}{$\mathrm{TP}$} & \multirow{2}{*}{ FP } & \multirow[b]{2}{*}{ FN } & \multirow{2}{*}{$\mathrm{TN}$} & \multicolumn{3}{|c|}{ Hasil } \\
\hline & & & & & Accuracy & Precission & Recall \\
\hline Glaukoma & 4 & 0 & 1 & 10 & $93,3 \%$ & $80 \%$ & $80 \%$ \\
\hline Normal & 5 & 2 & 0 & 8 & $86,6 \%$ & $100 \%$ & $100 \%$ \\
\hline $\begin{array}{l}\text { Retinopati } \\
\text { Diabetes }\end{array}$ & 4 & 0 & 1 & 10 & $93,3 \%$ & $80 \%$ & $80 \%$ \\
\hline \multicolumn{5}{|c|}{ Rata-Rata } & $91,06 \%$ & $86,6 \%$ & $86,6 \%$ \\
\hline
\end{tabular}

Berdasarkan hasil dan tabel-tabel diatas, dapat disimpulkan bahwa dataset dan citra fundus dapat diidentifikasi apakah dataset adalah citra fundus yang terjangkit glaukoma dan retinopati diabetes sehingga dapat disimpulkan bahwa jaringan syaraf tiruan dapat diimplementasikan untuk mengidentifikasi potensi glaukoma dan retinopati diabetes melalui citra fundus.

\section{KESIMPULAN}

Berdasarkan hasil penelitian yang dilakukan dapat disimpulkan bahwa diperoleh hasil pengujian terbaik yang menghasilkan rata-rata recall sebesar $86,6 \%$, rata-rata precission sebesar $86,6 \%$, dan rata-rata accuracy sebesar 91,06\%

\section{DAFTAR PUSTAKA}

[1] M. Clinic, Glaucoma - Symptoms and Causes, [Online], Available: https://www.mayoclinic.org/diseases-conditions/glaucoma/symptoms-causes/syc20372839. 
[2] M. Clinic, Diabetic retinopathy - Symptoms and Causes,[Online], Available: https://www.mayoclinic.org/diseases-conditions/diabetic-retinopathy/symptomscauses/syc-20371611.

[3] H. Fauzi and F. Hadi. 2016, Sistem Deteksi Glaukoma pada Foto Fundus Resolusi Tinggi, J. Elektro dan Telekomun, Terap., Vol. 2, No. 2.

[4] D. S. Tobias and A. R. Widiarti. 2016, Deteksi Glaukoma pada Citra Fundus Retina dengan Metode K-Nearest Neighbor, Seminar Nasional Ilmu Komputer, (SNIK).

[5] Y. S. Kurniawan, I. B. Hidayat, and S. Aulia. 2015, Deteksi dan Klasifikasi Tingkat Keparahan Retinopati Diabetes Dengan Menggunakan Metode Klasifikasi K - Nearest Neighbor Detection and Classification of Diabetic Retinopathy Severity Using K Nearest Neighbor Method, Vol. 2, No. 1, pp. 468-475.

[6] A. P. Pratama, R. D. Atmaja, and H. Fauzi. 2016, Deteksi Diabetes Retinopati pada Foto Fundus Menggunakan Color Histogram \& Transformasi Wavelet, eProceedings Eng., Vol. 3, No. 3.

[7] R. Y. Dillak, M. G. Bintiri, and S. Maroso. 2012, Identifikasi Fase Penyakit Retinopati Diabetes, Vol. 2012, No. semnasIF, pp. 126-133.

[8] F. H. Dalimunthe. 2016, Perancangan Aplikasi Mengidentifikasi Penyakit Mata Dengan Menggunakan Metode Backpropagation,” pp. 7-11.

[9] H. A. Risma, R. Patmasari, and R. Magdalena. 2019, Analisis Performansi Sistem Pendeteksi Katarak Menggunakan DCT ( Discrete Cosine Transform) dan Jaringan Saraf Tiruan Backpropagation (JST Backpropagation) Performance Analysis of Cataract Detection System Using DCT ( Discrete Cosine Transform ) and AR," Vol. 6, No. 1, pp. 364-371.

[10] B. Attila, B. Rüdiger, M. Andreas, H. Joachim, and M. Georg. 2013, Robust Vessel Segmentation in Fundus Images, Int. J. Biomed. Imaging, Vol. 2013, pp. 1-22. 